\title{
Effectiveness of Liquid-Liquid Extraction, Solid Phase Extraction, and Headspace Technique for Determination of Some Volatile Water-Soluble Compounds of Rose Aromatic Water
}

\author{
Hale Seçilmiş Canbay \\ Department of Bioengineering, Faculty of Engineering and Architecture, Mehmet Akif Ersoy University, 15030 Burdur, Turkey \\ Correspondence should be addressed to Hale Seçilmiş Canbay; halecanbay@gmail.com
}

Received 16 March 2017; Revised 5 June 2017; Accepted 14 June 2017; Published 16 July 2017

Academic Editor: Alberto Chisvert

Copyright (C) 2017 Hale Seçilmiş Canbay. This is an open access article distributed under the Creative Commons Attribution License, which permits unrestricted use, distribution, and reproduction in any medium, provided the original work is properly cited.

\begin{abstract}
Steam distillation is used to isolate scent of rose flowers. Rose aromatic water is commonly used in European cuisine and aromatherapy besides its use in cosmetic industry for its lovely scent. In this study, three different sampling techniques, liquid-liquid extraction (LLE), headspace technique (HS), and solid phase extraction (SPE), were compared for the analysis of volatile watersoluble compounds in commercial rose aromatic water. Some volatile water-soluble compounds of rose aromatic water were also analyzed by gas chromatography mass spectrometry (GCMS). In any case, it was concluded that one of the solid phase extraction methods led to higher recoveries for 2-phenylethyl alcohol (PEA) in the rose aromatic water than the liquid-liquid extraction and headspace technique. Liquid-liquid extraction method provided higher recovery ratios for citronellol, nerol, and geraniol than others. Ideal linear correlation coefficient values were observed by GCMS for quantitative analysis of volatile compounds $\left(r^{2} \geq 0.999\right)$. Optimized methods showed acceptable repeatability (RSDs $\left.<5 \%\right)$ and excellent recovery ( $\left.>95 \%\right)$. For compounds such as $\alpha$-pinene, linalool, $\beta$-caryophyllene, $\alpha$-humulene, methyl eugenol, and eugenol, the best recovery values were obtained with LLE and SPE.
\end{abstract}

\section{Introduction}

Aromatic waters are clear and saturated solutions of volatile oils, aromatic or volatile substances, and some water-soluble compounds of essential oil. Aromatic waters are generally produced by distillation of aromatic plants such as rose, thyme, and rosemary. Water acquired by concentration of steam during steam distillation to isolate the scent of aromatic plant flowers includes low amounts of essential oil. Rose aromatic water is liquid preparation obtained by hydrosol portion of the distillate of fresh rose petals and contains aromatic compounds in the form of either solution or suspended particles [1-4].

Rose aromatic water is a commercially important commodity since it is commonly used in European cuisine and aroma therapy. Due to its fragrance, rose aromatic water is used in cosmetic industry, food flavoring, soaps, and toiletry. It is also used in traditional medicine as antiseptic facial tonic, fever reducer, cooling assist, pain killer, astringent, mild laxative, and antibacterial and in treatment of sore throat, enlarged tonsils, cardiac troubles, eye diseases, gall stones, and gut troubles [3, 5-9].

In water distillation method, rose aromatic water contains very low amounts of (below $0.1 \%$ ) essential oil and its main component is phenylethyl alcohol $[4,10-16]$. Double distillation method is used as a traditional method. In this method, rose aromatic water is obtained in the final step of rose oil production, which is retained in large-capacity copper/ stainless steel distillation devices [17].

Due to the complexity of rose aromatic water and relatively low concentration of some terpenes, its analyses require isolation/preconcentration steps. The low concentration of volatile compounds makes enrichment necessary as the basis for identification and quantification, and among them liquidliquid extraction (LLE), solid phase extraction (SPE), solid 
TABLE 1: Main properties of solid phase cartridges used in isolation and concentration.

\begin{tabular}{|c|c|c|c|}
\hline & $\begin{array}{c}\text { Chemical description of } \\
\text { solid phase sorbent }\end{array}$ & Supplier & $\begin{array}{c}\text { Amount of solid phase } \\
\text { cartridge (mg) }\end{array}$ \\
\hline Sep Pak Plus C18 & Reversed phase & Waters & 360 \\
\hline Isolute ENV+ & $\begin{array}{c}\text { Hydroxylated polystyrene-divinyl } \\
\text { benzene copolymer }\end{array}$ & Biotage & 500 \\
\hline
\end{tabular}

phase microextraction (SPME), simultaneous distillation extraction (SDE), supercritical fluid extraction (SFE), headspace solid phase microextraction (HS-SPME), solid phase extraction (SPE), and stir bar sorptive extraction (SBSE) have been extensively studied [2-4,10-16, 18-36].

This study is aimed at selecting the best extraction technique for studying the volatile composition of rose water, and LLE, SPE, and HS technique were used for quantitative determination of volatile compounds of aromatic rose water. Numerous studies have been carried out on chemical composition of rose aromatic water $[3,4,10-16,19]$ from different countries but analytical values (extraction efficiency, detection limit, etc.) were not included in these studies. To our knowledge, this present study is the first involving these parameters.

\section{Materials and Methods}

2.1. Chemicals and Reagents. Methanol (HPLC grade), nhexane (HPLC grade), n-pentane (HPLC grade), chloroform (GC grade), dichloromethane (HPLC grade), and ethyl acetate (HPLC grade) were obtained from Merck (Germany) and Sigma Aldrich (USA). Sep Pak Plus C18 cartridges (Waters, USA) and Isolute ENV+ (Biotage, USA) were used for solid phase extraction. Chemical standards of $\alpha$-pinene, linalool, $\alpha$-humulene ( $\alpha$-caryophyllene), nerol, 2-phenylethyl alcohol (PEA), $\beta$-caryophyllene, citronellol, geraniol, methyl eugenol, and eugenol were supplied from Sigma Aldrich (USA) while $\mathrm{NaCl}$ was purchased from Merck (Germany).

2.2. Aromatic Rose Water Samples. Commercial rose water samples were purchased from a local store.

2.3. Isolation and Preconcentration Techniques. Three different methods were used for the isolation and concentration of volatile compounds from rose aromatic water as explained below.

2.3.1. Liquid-Liquid Extraction Procedure. The volatile components were extracted by the methods of Hernanz et al. [33] and Cabredo-Pinillos et al. [34]. Briefly, $200 \mathrm{~mL}$ of sample containing $4 \mathrm{~g}$ of $\mathrm{NaCl}$ was placed in a $250 \mathrm{~mL}$ glass flask. The extraction was performed with $5 \mathrm{~mL}$ of chloroform, dichloromethane, n-hexane, and ethyl acetate. The flasks were introduced into the ultrasonic bath (Bandelin Sonorex, Germany) and sonicated for $30 \mathrm{~min}$ at $25^{\circ} \mathrm{C}$. The organic layer was then separated via pipetting. All samples were extracted in duplicate. Finally, $1 \mu \mathrm{L}$ of aliquots was injected into a GCMS system.
TABLE 2: Headspace sampler setup parameters.

\begin{tabular}{lc}
\hline Parameter & Working condition \\
\hline Oven temperature & $75^{\circ} \mathrm{C}$ \\
Loop temperature & $90^{\circ} \mathrm{C}$ \\
Transfer line temperature & $100^{\circ} \mathrm{C}$ \\
Vial pressure & $0.23 \mathrm{psi}$ \\
Vial flow & $20 \mathrm{~mL} / \mathrm{min}$ \\
Carrier pressure & $15 \mathrm{psi}$ \\
\hline
\end{tabular}

2.3.2. Solid Phase Extraction Procedure. Two different solid phase cartridges (Sep Pak Plus C18 cartridges and Isolute $\mathrm{ENV}+$ ) were tested for the isolation and concentration of volatile compounds from rose aromatic water (Table 1). The solid phase extractions were carried out in a Visiprep SPE vacuum manifold (12-port model) from Supelco (Supelco, USA). Solid phase extractions were performed according to the method developed by López et al. [20] and Piñeiro et al. [21]. Cartridges were placed in the manifold system and activated with $4 \mathrm{~mL}$ dichloromethane, $4 \mathrm{~mL}$ of methanol, and finally rinsing $4 \mathrm{~mL}$ of water. Then $100 \mathrm{~mL}$ rose aromatic water samples were passed through the cartridges by vacuum manifold, after which the sorbents were dried. Volatile compounds were eluted from the cartridges using an organic solvent (n-pentane, $n$-hexane, dichloromethane, and methanol).

2.3.3. Headspace Extraction. Isolation and preconcentration of volatile compounds were achieved using a 7697A headspace sampler apparatus (Agilent, USA). $4 \mathrm{~mL}$ volume of sample was used for analysis. Table 2 shows the headspace sampler setup parameters for the headspace sampler apparatus. The headspace transfer line was directly passed through the 7890A GC injector port and connected to the GC CP-Wax $52 \mathrm{CB}$ column using a universal capillary column connector.

2.4. Standard Solutions, Calibration Curves, and Recovery Studies. Stock standard solutions of $10 \mathrm{mg} / \mathrm{mL}$ of each compound were prepared in methanol and stored at $-20^{\circ} \mathrm{C}$. In both cases, different working standard solutions were prepared by dilution in the same solvent. Six concentrations were used for calibration curves of volatile compounds. The average recoveries of the analytes were determined by comparing the peak areas obtained from each volatile compound.

2.5. Chromatography and Apparatus. Apparatus GCMS was Agilent 7890A gas chromatograph equipped with a 5975 
TABLE 3: Retention time $\left(R_{t}\right)$ and performance characteristic obtained by GCMS and HS-GCMS.

\begin{tabular}{lccccccc}
\hline Compounds & $\begin{array}{c}R_{t} \\
(\mathrm{~min})\end{array}$ & GCMS & HS-GCMS & $\begin{array}{c}\mathrm{LOD}_{\mathrm{GCMS}} \\
(\mu \mathrm{g} / \mathrm{L})\end{array}$ & $\begin{array}{c}\mathrm{LOQ}_{\mathrm{GCMS}} \\
(\mu \mathrm{g} / \mathrm{L})\end{array}$ & $\begin{array}{c}\mathrm{LOD}_{\mathrm{HS}-\mathrm{GCMS}} \\
(\mu \mathrm{g} / \mathrm{L})\end{array}$ & $\begin{array}{c}\mathrm{LOQ}_{\mathrm{HS}-\mathrm{CMS}} \\
(\mu \mathrm{g} / \mathrm{L})\end{array}$ \\
\hline$\alpha$-Pinene & 4.3 & 0.9997 & 0.9990 & 1.240 & 4.092 & 3.750 & 12.375 \\
Linalool & 9.8 & 0.9999 & 0.9990 & 0.360 & 1.188 & 1.143 \\
$\beta$-Caryophyllene & 10.4 & 0.9999 & 0.9990 & 0.680 & 2.244 & 2.100 & 6.772 \\
$\alpha$-Humulene & 11.0 & 0.9996 & 0.9990 & 0.720 & 2.376 & 2.250 & 7.425 \\
Citronellol & 11.4 & 0.9995 & 0.9990 & 0.380 & 1.254 & 1.210 & 3.993 \\
Nerol & 11.8 & 0.9994 & 0.9990 & 1.000 & 3.300 & 3.600 & 11.880 \\
Geraniol & 12.2 & 0.9990 & 0.9990 & 1.600 & 5.280 & 4.650 & 15.25 \\
PEA & 13.1 & 0.9990 & 0.9990 & 1.000 & 3.300 & 2.780 & 9.174 \\
Methyl eugenol & 14.4 & 0.9996 & 0.9990 & 0.780 & 2.574 & 2.455 & 8.102 \\
Eugenol & 17.6 & 0.9999 & 0.9990 & 0.600 & 1.980 & 1.890
\end{tabular}

mass detector (MSD), a 7693B automatic sampler, and a MSDCHEM (Agilent, USA) data system. Analytes were separated in a fused silica capillary column CP-Wax $52 \mathrm{CB}$ stationary phase $(50 \mathrm{~m} \times 0.25 \mathrm{~mm}$; film thickness $0.2 \mu \mathrm{m})$ (Agilent, USA). Oven temperature program was as follows: initial temperature $60^{\circ} \mathrm{C}$, held for $1 \mathrm{~min}$, increased to $220^{\circ} \mathrm{C}$ at $2^{\circ} \mathrm{C} / \mathrm{min}$, and held at $20 \mathrm{~min}$. The carrier gas (helium) flow rate was 15 psi. Splitless injection of a $1 \mu \mathrm{L}$ volume was carried out at $250^{\circ} \mathrm{C}$. Temperature of the detector was $250^{\circ} \mathrm{C}$. MSD conditions were ion source temperature, $230^{\circ} \mathrm{C}$; electron energy, $70 \mathrm{eV}$; mass scan range, 30-500 amu. The same system and temperature program were used in HS analysis. A 7697A headspace sampler was used instead of automatic sampler [3].

2.6. Statistical Analyses and Validation Procedures. Limit of detection (LOD), limit of quantification (LOQ), linearity of calibration, intraday and interday accuracy, precision, and recovery were estimated for the validation of this method. Six concentrations of standard solutions were prepared. Each standard solutions (volatile compounds) concentration was measured in five replicates. Calibration curves for the studied volatile compounds were preprepared by plotting peak areas versus concentrations for GCMS and HS-GCMS. We defined the LOD was defined as three times the background noise of the chromatographic instrument. The extraction recovery was determined by spiking blank rose water with each compound (standard addition method) in three replicates; they were extracted as previously described. Standard solutions of target compounds were analyzed five times in a day and once a day on three consecutive days for intraday and interday precisions, respectively.

\section{Results and Discussion}

Ten volatile water-soluble compounds in rose aromatic water were used as target compounds during the LLE, SPE, and HS method development: $\alpha$-pinene, linalool, $\alpha$-humulene, nerol, PEA, $\beta$-caryophyllene, citronellol, geraniol, methyl eugenol, and eugenol.
3.1. Optimization of SPE and Eluting Solvent. Two different kinds of solid phase sorbents were studied, one of them with reversed solid phase $(\mathrm{C18})$ and the other one with hydroxylated polystyrene-divinyl benzene copolymer $(\mathrm{ENV}+)$ solid phase. $2 \mathrm{~mL}$ of each eluting solvent was used to recover terpenoid ingredients from the solid phase sorbents. n-Pentane and n-hexane were the worst sorbents eluting solvents. Recoveries $<50 \%$ were obtained for all volatile water-soluble compounds for two kinds of solid phase sorbents. Methanol was selected as the best eluting solvent for compound elution from the Sep Pak Plus C18 cartridge. Also dichloromethane was the best eluting solvent for volatile water-soluble compounds elution from the Isolute ENV+. Piñeiro et al. [21] studied the effectiveness of four different eluting solvents (n-pentane, methanol, dichloromethane, and ethanol) for the SPE of wine terpenoids and concluded that the highest isolation and concentration efficiency was achieved by using dichloromethane as the eluting solvent.

3.2. Optimization of LLE and Extraction Solvent. Complete extraction from rose aromatic water was achieved by using chloroform, dichloromethane, ethyl acetate, and n-hexane. LLE of rose aromatic water with chloroform, dichloromethane, and ethyl acetate provided target compounds in rose aromatic water extract in quantitative determination. nHexane was worst LLE solvents.

Agarwal et al. [4] studied the effectiveness of different eluting solvents (dichloromethane, chloroform, hexane, and benzene) for the LLE of rose water terpenoids and concluded that the highest isolation and optimum results were achieved by using dichloromethane as extraction solvent.

3.3. Linearity of Calibration Curves and Limits of Detection and Quantification. The retention time $\left(R_{t}\right)$, linearity $\left(r^{2}\right)$, LOD, and LOQ were summarized in Table 3. A regression equation was obtained with good linearity $\left(r^{2} \geq 0.999\right)$ for GCMS and for HS-GCMS.

The $r^{2}$ values $\geq 0.999$ for target compounds. Lei et al. [15] reported the PEA in rose water and the acquired $r^{2}$ value was 1.0000. Piñeiro et al. [21] studied SPE methods and 
TABLE 4: Intraday and interday precisions for GCMS.

\begin{tabular}{|c|c|c|c|c|c|c|}
\hline \multirow{3}{*}{ Compounds } & \multicolumn{3}{|c|}{ Precision (RSD, \%) } & \multicolumn{3}{|c|}{ Precision (RSD, \%) } \\
\hline & \multicolumn{3}{|c|}{ Intraday $(\mathrm{mg} / \mathrm{L})$} & \multicolumn{3}{|c|}{ Interday (mg/L) } \\
\hline & 2.50 & 5.00 & 10.00 & 2.50 & 5.00 & 10.00 \\
\hline$\alpha$-Pinene & $2.48(0.12)$ & $5.11(0.10)$ & $9.98(0.10)$ & $2.45(0.15)$ & $4.98(0.14)$ & $9.95(0.13)$ \\
\hline Linalool & $2.52(0.15)$ & $5.05(0.15)$ & $10.08(0.14)$ & $2.51(0.17)$ & $4.99(0.16)$ & $9.98(0.16)$ \\
\hline$\beta$-Caryophyllene & $2.45(0.13)$ & $5.01(0.13)$ & $9.95(0.15)$ & $2.43(0.17)$ & $4.98(0.17)$ & $9.96(0.16)$ \\
\hline$\alpha$-Humulene & $2.43(0.15)$ & $5.05(0.15)$ & $9.98(0.13)$ & $2.42(0.18)$ & $4.96(0.16)$ & $9.94(0.16)$ \\
\hline Citronellol & $2.52(0.11)$ & $5.03(0.10)$ & $10.02(0.13)$ & $2.49(0.18)$ & $4.98(0.18)$ & $9.95(0.18)$ \\
\hline Nerol & $2.48(0.15)$ & $4.95(0.14)$ & $9.95(0.15)$ & $2.44(0.18)$ & $4.95(0.18)$ & $9.93(0.17)$ \\
\hline Geraniol & $2.47(0.13)$ & $5.02(0.14)$ & $9.95(0.13)$ & $2.48(0.15)$ & $4.98(0.15)$ & $9.95(0.15)$ \\
\hline PEA & $2.51(0.14)$ & $5.05(0.13)$ & $10.02(0.12)$ & $2.53(0.17)$ & $4.97(0.16)$ & $9.97(0.17)$ \\
\hline Methyl eugenol & $2.46(0.20)$ & $4.96(0.19)$ & $9.98(0.20)$ & $2.48(0.22)$ & $4.96(0.20)$ & $9.95(0.20)$ \\
\hline Eugenol & $2.49(0.23)$ & $5.11(0.20)$ & $10.08(0.21)$ & $2.45(0.24)$ & $5.05(0.22)$ & $9.99(0.23)$ \\
\hline
\end{tabular}

TABLE 5: Intraday and interday precisions for HS-GCMS.

\begin{tabular}{|c|c|c|c|c|c|c|}
\hline \multirow{3}{*}{ Compounds } & \multicolumn{3}{|c|}{ Precision (RSD, \%) } & \multicolumn{3}{|c|}{ Precision (RSD, \%) } \\
\hline & \multicolumn{3}{|c|}{ Intraday (mg/L) } & \multicolumn{3}{|c|}{ Interday $(\mathrm{mg} / \mathrm{L})$} \\
\hline & 2.50 & 5.00 & 10.00 & 2.50 & $\frac{5.00}{589(036)}$ & $\frac{10.00}{10.18(0.35)}$ \\
\hline$\alpha$-Pinene & $2.42(0.32)$ & $4.88(0.30)$ & $10.21(0.31)$ & $2.40(0.35)$ & $\begin{array}{l}5.89(0.36) \\
4.95(0.38)\end{array}$ & $\begin{array}{r}10.18(0.35) \\
9.95(0.36)\end{array}$ \\
\hline $\begin{array}{l}\text { Linalool } \\
\beta \text {-Caryophyllene }\end{array}$ & $\begin{array}{l}2.47(0.36) \\
2.47(0.37)\end{array}$ & $\begin{array}{l}5.11(0.35) \\
4.97(0.35)\end{array}$ & $\begin{array}{l}9.88(0.35) \\
9.85(0.37)\end{array}$ & $\begin{array}{l}2.45(0.38) \\
2.46(0.40)\end{array}$ & $4.95(0.39)$ & $\begin{array}{l}9.95(0.36) \\
9.84(0.39)\end{array}$ \\
\hline$\alpha$-Humulene & $2.44(0.38)$ & $4.96(0.38)$ & $9.88(0.37)$ & $2.44(0.41)$ & $4.94(0.42)$ & $9.85(0.40)$ \\
\hline Citronellol & $2.45(0.30)$ & $4.85(0.29)$ & $9.85(0.30)$ & $2.42(0.33)$ & $4.83(0.32)$ & $9.88(0.32)$ \\
\hline Nerol & $2.52(0.35)$ & $5.08(0.34)$ & $9.86(0.35)$ & $2.49(0.37)$ & $4.95(0.36)$ & $9.85(0.36)$ \\
\hline Geraniol & $2.48(0.31)$ & $4.94(0.31)$ & $9.91(0.30)$ & $2.44(0.34)$ & $4.90(0.33)$ & $9.95(0.33)$ \\
\hline PEA & $2.45(0.32)$ & $4.89(0.32)$ & $9.98(0.33)$ & $2.47(0.35)$ & $4.87(0.34)$ & $9.95(0.34)$ \\
\hline Methyl eugenol & $2.53(0.41)$ & $5.10(0.42)$ & $10.13(0.41)$ & $2.55(0.45)$ & $4.99(0.43)$ & $10.03(0.43)$ \\
\hline Eugenol & $2.49(0.43)$ & $5.11(0.43)$ & $10.08(0.42)$ & $2.45(0.47)$ & $5.05(0.45)$ & $9.99(0.46)$ \\
\hline
\end{tabular}

found $r^{2}$ values were $>0.999$. Vila et al. [35] reported volatile compounds in wine and linear correlation coefficients were $\geq 0.994$. Won et al. [36] indicated PEA values in Bulgarian rose and Provence lavender oil and $r^{2}$ value for PEA was 0.9814 .

The LOD values were between 0.360 and $1.600 \mu \mathrm{g} / \mathrm{L}$ for studied compounds for GCMS and between 1.143 and $4.650 \mu \mathrm{g} / \mathrm{L}$ for studied compounds for HS-GCMS. The relatively low values indicated that the method possessed good sensitivity. In the HS-GCMS technique, the LOD values were slightly higher because the noise ratio was slightly higher than the GCMS technique. Piñeiro et al. [21] used SPE methods and obtained LOD values between 0.33 and $3.37 \mu \mathrm{g} / \mathrm{L}$. Sánchez-Palomo et al. [27] evaluated the LLE, SPE, and SDE methods, and the obtained LOD values were within $0.01-0.02 \mu \mathrm{g} / \mathrm{L}, 0.02-0.04 \mu \mathrm{g} / \mathrm{L}$, and $0.01-0.08 \mu \mathrm{g} / \mathrm{L}$, respectively. Won et al. [36] reported PEA values in Bulgarian rose and Provence lavender oil and LOD value for PEA was $0.77 \mathrm{ng} / \mathrm{mL}$.

Precision and repeatability are summarized in Tables 4 and 5 . The intraday and interday relative standard deviations
(RSDs) for target compounds were within $0.10 \%-0.23 \%$ and $0.13 \%-0.24 \%$, respectively, for GCMS and within $0.29 \%-0.43 \%$ and $0.32 \%-0.47 \%$, respectively, for HS-GCMS. The RSD values were less than $5 \%$ in all experiments. Lei et al. [15] studied the PEA in rose water and obtained intraday and interday RSDs of PEA $0.15 \%$ and $0.19 \%$, respectively.

3.4. Recoveries. Recovery test was carried out using the method of standard addition. Rose water samples were spiked with three different concentrations of standard solutions and analyzed. The recovery of PEA ranged from $32.22 \%$ to $69.45 \%$, with RSDs less than $5.00 \%$ for LLE. Recovery values ranged from 25.76 to $98.86 \%$ for chloroform as an extraction solvent while they varied from 32.07 to $98.81 \%$ for dichloromethane. For ethyl acetate, the range of recovery values was between 57.49 and $95.29 \%$, which was generally higher than that of nhexane (32.71 to $67.35 \%$ ) (Table 6).

When the C18 cartridge was used, the recovery values were between 80.44 and $99.75 \%$. For ENV+ recoveries ranged from 32.96 to $87.22 \%$. For HS-GCMS recovery ranged between 33.53 and $116.90 \%$ (Table 7 ). 
TABLE 6: LLE average recovery.

\begin{tabular}{|c|c|c|c|c|}
\hline \multirow[t]{2}{*}{ Compounds } & \multicolumn{4}{|c|}{$\begin{array}{c}\text { Average percent recovery and RSD values (\%) } \\
\text { Extraction solvent type }\end{array}$} \\
\hline & Chloroform & Dichloromethane & Ethyl acetate & n-Hexane \\
\hline$\alpha$-Pinene & $31.43(1.10)$ & $32.07(0.98)$ & $57.49(0.93)$ & $32.71(0.87)$ \\
\hline Linalool & $25.76(1.35)$ & $97.86(0.78)$ & $95.29(0.81)$ & $61.01(1.23)$ \\
\hline$\beta$-Caryophyllene & $90.72(0.92)$ & $94.22(0.81)$ & $81.28(0.98)$ & $61.96(1.35)$ \\
\hline$\alpha$-Humulene & $90.10(0.85)$ & $84.25(1.11)$ & $80.65(0.98)$ & $46.40(1.42)$ \\
\hline Citronellol & $97.15(0.81)$ & $87.50(0.99)$ & $87.39(1.01)$ & $61.76(1.19)$ \\
\hline Nerol & $95.48(1.04)$ & $97.47(0.85)$ & $85.56(1.05)$ & $50.96(1.17)$ \\
\hline Geraniol & $98.86(0.83)$ & $86.61(0.88)$ & $95.24(0.85)$ & $52.29(1.10)$ \\
\hline PEA & $69.45(0.95)$ & $65.57(1.22)$ & $67.38(1.25)$ & $32.22(1.55)$ \\
\hline Methyl eugenol & $84.58(0.95)$ & $94.63(0.80)$ & $77.67(1.18)$ & $67.35(1.21)$ \\
\hline Eugenol & $88.22(0.90)$ & $98.81(0.75)$ & $91.80(0.95)$ & $49.36(1.30)$ \\
\hline
\end{tabular}

TABLE 7: SPE average recovery.

\begin{tabular}{lccc}
\hline Compounds & & \multicolumn{2}{c}{$\begin{array}{c}\text { Average percent recovery and RSD values (\%) } \\
\text { Extraction type } \\
\text { ENV+ }\end{array}$} \\
\hline$\alpha$-Pinene & C18 & $32.96(1.20)$ & HS-GCMS \\
Linalool & $91.45(0.78)$ & $76.61(0.90)$ & $60.11(2.13)$ \\
$\beta$-Caryophyllene & $86.44(0.98)$ & $59.56(0.93)$ & $61.48(2.25)$ \\
$\alpha$-Humulene & $80.44(0.75)$ & $59.03(1.02)$ & $59.03(2.35)$ \\
Citronellol & $85.85(0.92)$ & $75.87(0.91)$ & $45.32(3.12)$ \\
Nerol & $85.69(0.96)$ & $72.71(0.95)$ & $58.21(2.01)$ \\
Geraniol & $86.46(0.96)$ & $73.04(1.05)$ & $46.39(2.41)$ \\
PEA & $85.73(0.90)$ & $80.33(0.85)$ & $48.00(2.39)$ \\
Methyl eugenol & $99.75(0.83)$ & $85.22(1.00)$ & $33.53(2.17)$ \\
Eugenol & $84.20(0.96)$ & $87.22(0.96)$ & $116.90(1.94)$ \\
\hline
\end{tabular}

Lei et al. [15] reported that recovery values were within 99.3-101.0\% for PEA in rose water. Piñeiro et al. [21] found that recovery values were within $96.8-100.8 \%$ for optimized method. Hernanz et al. [33] evaluated the effectiveness of different extraction methods (LLE and SPE), and the recovery values for PEA, linalool, citronellol, nerol, and geraniol were 92.6\%, 109.6\%, 97.2\%, 97\%, and 99.3\% for LLE 1, 18.6\%, 19.7\%, $19.4 \%, 19.3 \%$, and $20.7 \%$ for LLE 2 , and $96.5 \%, 98.7 \%, 88.9 \%$, $88.2 \%$, and $97.4 \%$ for SPE, respectively.

3.5. Chemical Profiles of Rose Aromatic Water. The predominant components of rose water volatiles are PEA, citronellol, geraniol, nerol, and methyl eugenol [3, 4, 10-16, 19]. In addition to these components, $\alpha$-pinene, linalool, $\beta$-caryophyllene, and $\alpha$-humulene components were also included in our study. These components are also found in rose oil and rose water [3, 4, 10-19]. In rose aromatic water samples, PEA $(1677.38 \pm 0.14 \mu \mathrm{g} / \mathrm{g})$, citronellol $(418.21 \pm$ $0.23 \mu \mathrm{g} / \mathrm{g})$, nerol $(183.77 \pm 0.44 \mu \mathrm{g} / \mathrm{g})$, and geraniol $(443.34 \pm$ $0.12 \mu \mathrm{g} / \mathrm{g}$ ) were found as main compounds followed by $\alpha$-pinene $(63.62 \pm 0.88 \mu \mathrm{g} / \mathrm{g})$, linalool $(73.57 \pm 0.38 \mu \mathrm{g} / \mathrm{g})$, $\alpha$-humulene $(22.93 \pm 0.30 \mu \mathrm{g} / \mathrm{g})$, eugenol $(66.25 \pm 0.52 \mu \mathrm{g} / \mathrm{g})$, and methyl eugenol $(55.10 \pm 0.28 \mu \mathrm{g} / \mathrm{g}) . \beta$-Caryophyllene was not detected in rose aromatic water samples.

\section{Conclusions}

This study was carried out to quantify the volatile watersoluble compounds of rose aromatic water samples using different isolation and preconcentration techniques. The recoveries obtained using samples spiked with standard target compounds ranged within 80.44 and $99.75 \%$ for $\mathrm{C} 18$ cartridge, 32.96 and $87.22 \%$ for ENV+, 33.53 and $116.90 \%$ for HS, 25.76 and $98.86 \%$ for chloroform, 32.07 and $98.81 \%$ for dichloromethane, 57.49 and $95.29 \%$ for ethyl acetate, and 32.71 and $67.35 \%$ for $n$-hexane. The RSD values were less than $5 \%$ in all experiments. The method showed good recoveries and high repeatabilities. PEA was the main volatile watersoluble constituent of aromatic rose water. 
The SPE method is a faster technique than LLE and HS but the HS technique is achieved without any solvent. Different solvents such as chloroform, dichloromethane, ethyl acetate, n-pentane, and n-hexane are used in SPE and LLE techniques, which may cause contamination of the environment at different levels.

\section{Conflicts of Interest}

The author declares no conflicts of interest regarding the publication of this paper.

\section{Acknowledgments}

The author thanks Professor Dr. Yusuf Yilmaz for technical evaluation of the study and the Scientific and Technology Application and Research Center of Mehmet Akif Ersoy University, Burdur, for providing facilities for analyses.

\section{References}

[1] D. Ciccarelli, C. Noccioli, and L. Pistelli, "Chemical composition of essential oils and aromatic waters from different Italian Anthemis maritima populations," Chemistry and Biodiversity, vol. 10, no. 9, pp. 1667-1682, 2013.

[2] S. Gallori, G. Flamini, A. R. Bilia, I. Morelli, A. Landini, and F. F. Vincieri, "Chemical composition of some traditional herbal drug preparations: essential oil and aromatic water of costmary (Balsamita suaveolens Pers.)," Journal of Agricultural and Food Chemistry, vol. 49, no. 12, pp. 5907-5910, 2001.

[3] H. Baydar, H. Kuleasan, N. Kara, H. Secilmis-Canbay, and S. Kineci, "The effects of pasteurization, ultraviolet radiation and chemiclal preservatives on microbial spoilage and scent composition of rose water," Journal of Essential Oil-Bearing Plants, vol. 16, no. 2, pp. 151-160, 2013.

[4] S. G. Agarwal, A. Gupta, B. K. Kapahi, Baleshwar, R. K. Thappa, and O. P. Suri, "Chemical composition of rose water volatiles," Journal of Essential Oil Research, vol. 17, no. 3, pp. 265-267, 2005.

[5] M. H. Boskabady, A. Vatanprast, H. Parsaee, and M. Boskabady, "Possible mechanism of inotropic and chronotropic effects of Rosa damascena on isolated guinea pig heart," DARU, Journal of Pharmaceutical Sciences, vol. 21, no. 1, article no. 38, pp. 2-7, 2013.

[6] D. P. Anonis, "The application of carnation in perfumery," Flavour and Fragrance Journal, vol. 1, no. 1, pp. 9-15, 1985.

[7] S. R. Hunt, "The rose in pharmacy," The Pharmaceutical Journal, vol. 189, pp. 589-591, 1962.

[8] W. Schweisheimer, "Roses in manufacture of perfumes," Parfums Cosmétique Savons, vol. 4, pp. 62-65, 1961.

[9] V. K. Kaul, Damask Rose-Cultivation And Processing in Supplement to Cultivation and Utilization of Aromatic Plants, Regional Research Laboratory, Jammu, India, 1998.

[10] M. Moein, M. M. Zarshenas, and S. Delnavaz, "Chemical composition analysis of rose water samples from Iran," Pharmaceutical Biology, vol. 52, no. 10, pp. 1358-1361, 2014.

[11] S. Erbas and H. Baydar, "Variation in scent compounds of oilbearing rose (Rosa damascena Mill.) Produced by headspace solid phase microextraction, hydrodistillation and solvent extraction," Records of Natural Products, vol. 10, no. 5, pp. 555$565,2016$.
[12] M. Kürkcüoglu and H. C. Baser, "Studies on Turkish rose concrete, absolute, and hydrosol," Chemistry of Natural Compounds, vol. 39, no. 5, pp. 457-464, 2003.

[13] R. S. Verma, R. C. Padalia, A. Chauhan, A. Singh, and A. K. Yadav, "Volatile constituents of essential oil and rose water of damask rose (Rosa damascena mill.) cultivars from north indian hills," Natural Product Research, vol. 25, no. 17, pp. 1577-1584, 2011.

[14] M. H. Eikani, F. Golmohammad, S. Rowshanzamir, and M. Mirza, "Recovery of water-soluble constituents of rose oil using simultaneous distillation-extraction," Flavour and Fragrance Journal, vol. 20, no. 6, pp. 555-558, 2005.

[15] G. Lei, L. Wang, X. Liu, and A. Zhang, "Fast quantification of phenylethyl alcohol in rose water and chemical profiles of rose water and oil of rosa damascena and rosa rugosa from southeast China," Journal of Liquid Chromatography and Related Technologies, vol. 38, no. 7, pp. 823-832, 2015.

[16] K. Hosni, A. Kerkenni, W. Medfei, N. Ben Brahim, and H. Sebei, "Volatile Oil Constituents of," Organic Chemistry International, vol. 2010, pp. 1-7, 2010.

[17] H. Baydar, H. Schulz, H. Krüger, S. Erbas, and S. Kineci, "Influences of fermentation time, hydro-distillation time and fractions on essential oil composition of Damask Rose (Rosa damascena Mill.)," Journal of Essential Oil-Bearing Plants, vol. 11, no. 3, pp. 224-232, 2008.

[18] K. G. D. Babu, B. Singh, V. P. Joshi, and V. Singh, "Essential oil composition of Damask rose (Rosa damascena Mill.) distilled under different pressures and temperatures," Flavour and Fragrance Journal, vol. 17, no. 2, pp. 136-140, 2002.

[19] S. Ulusoy, G. Tinaz, and H. Secilmis-Canbay, "Tocopherol, carotene, phenolic contents and antibacterial properties of rose essential oil, hydrosol and absolute," Current Microbiology, vol. 59, no. 5, pp. 554-558, 2009.

[20] R. López, M. Aznar, J. Cacho, and V. Ferreira, “Determination of minor and trace volatile compounds in wine by solid-phase extraction and gas chromatography with mass spectrometric detection," Journal of Chromatography A, vol. 966, no. 1-2, pp. 167-177, 2002.

[21] Z. Piñeiro, M. Palma, and C. G. Barroso, "Determination of terpenoids in wines by solid phase extraction and gas chromatography," Analytica Chimica Acta, vol. 513, no. 1, pp. 209214, 2004.

[22] B. T. Weldegergis, A. M. Crouch, T. Górecki, and A. de Villiers, "Solid phase extraction in combination with comprehensive two-dimensional gas chromatography coupled to time-of-flight mass spectrometry for the detailed investigation of volatiles in South African red wines," Analytica Chimica Acta, vol. 701, no. 1, pp. 98-111, 2011.

[23] M. Dziadas and H. H. Jelen, "Analysis of terpenes in white wines using SPE-SPME-GC/MS approach," Analytica Chimica Acta, vol. 677, no. 1, pp. 43-49, 2010.

[24] J. Wang, D. L. Capone, K. L. Wilkinson, and D. W. Jeffery, "Chemical and sensory profiles of rosé wines from Australia," Food Chemistry, vol. 196, pp. 682-693, 2016.

[25] B. Mendes, J. Gonalves, and J. S. Câmara, "Effectiveness of highthroughput miniaturized sorbent- and solid phase microextraction techniques combined with gas chromatography-mass spectrometry analysis for a rapid screening of volatile and semivolatile composition of wines - A comparative study," Talanta, vol. 88, pp. 79-94, 2012. 
[26] V. Pereira, J. Cacho, and J. C. Marques, "Volatile profile of Madeira wines submitted to traditional accelerated ageing," Food Chemistry, vol. 162, pp. 122-134, 2014.

[27] E. Sánchez-Palomo, M. E. Alañón, M. C. Díaz-Maroto, González-Vínas M. A., and M. S. Pérez-Coello, "Comparison of extraction methods for volatile compounds of Muscat grape juice," Talanta, vol. 79, no. 3, pp. 871-876, 2009.

[28] S. M. Pourmortazavi and S. S. Hajimirsadeghi, "Supercritical fluid extraction in plant essential and volatile oil analysis," Journal of Chromatography A, vol. 1163, no. 1-2, pp. 2-24, 2007.

[29] B. X. Jian, W. C. Jing, and M. Xu, "Supercritical fluid $\mathrm{CO}_{2}$ extraction of essential oil from Marchantia convoluta: global yields and extract chemical composition," Electronic Journal of Biotechnology, vol. 10, no. 1, pp. 141-148, 2007.

[30] M. A. Ferhat, B. Y. Meklati, and F. Chemat, "Comparison of different isolation methods of essential oil from Citrus fruits: cold pressing, hydrodistillation and microwave 'dry' distillation," Flavour and Fragrance Journal, vol. 22, no. 6, pp. 494-504, 2007.

[31] N. M. D. O. Arcanjo, T. K. A. Bezerra, F. L. H. da Silva, and M. S. Madruga, "Optimization of the HS-SPME-GC/MS technique for determining volatile compounds in red wines made from Isabel grapes (Vitis labrusca)," Food Science and Technology, vol. 35, no. 4, pp. 676-682, 2015.

[32] G. Antalick, M.-C. Perello, and G. de Revel, "Development, validation and application of a specific method for the quantitative determination of wine esters by headspace-solidphase microextraction-gas chromatography-mass spectrometry," Food Chemistry, vol. 121, no. 4, pp. 1236-1245, 2010.

[33] D. Hernanz, V. Gallo, Á. F. Recamales, A. J. Meléndez-Martínez, and F. J. Heredia, "Comparison of the effectiveness of solidphase and ultrasound-mediated liquid-liquid extractions to determine the volatile compounds of wine," Talanta, vol. 76, no. 4, pp. 929-935, 2008.

[34] S. Cabredo-Pinillos, T. Cedrón-Fernández, M. GonzálezBriongos, L. Puente-Pascual, and C. Sáenz-Barrio, "Ultrasoundassisted extraction of volatile compounds from wine samples: Optimisation of the method," Talanta, vol. 69, no. 5, pp. 11231129, 2006.

[35] D. H. Vila, F. J. Heredia Mira, R. Beltran Lucena, and M. A. Fernández Recamales, "Optimization of an extraction method of aroma compounds in white wine using ultrasound," Talanta, vol. 50, no. 2, pp. 413-421, 1999.

[36] M.-M. Won, E.-J. Cha, O.-K. Yoon, N.-S. Kim, K. Kim, and D.S. Lee, "Use of headspace mulberry paper bag micro solid phase extraction for characterization of volatile aromas of essential oils from Bulgarian rose and Provence lavender," Analytica Chimica Acta, vol. 631, no. 1, pp. 54-61, 2009. 

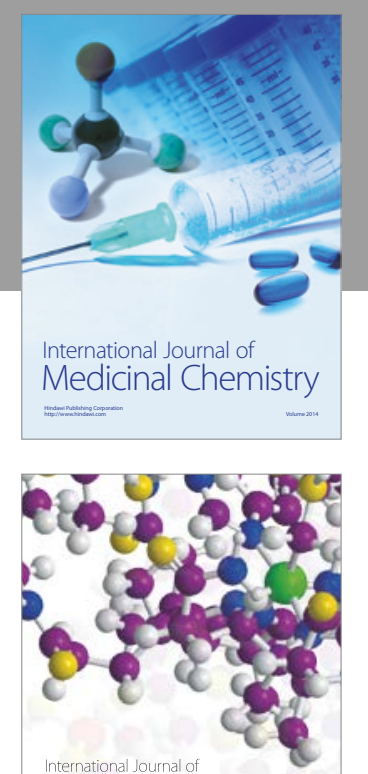

Carbohydrate Chemistry

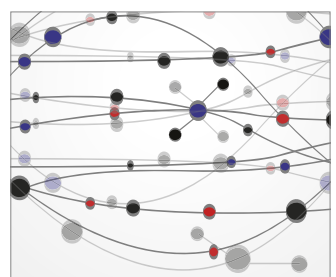

The Scientific World Journal
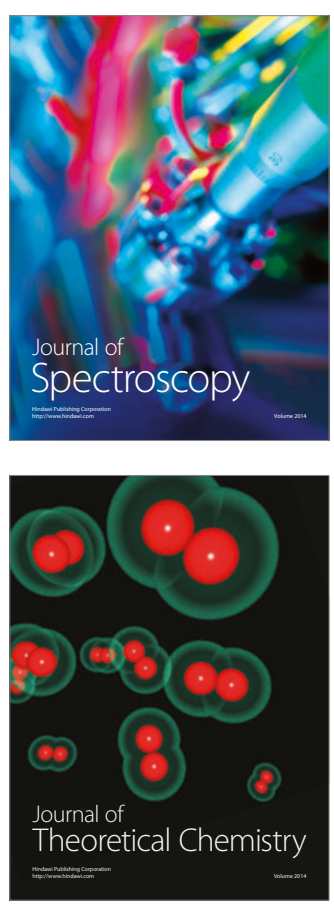
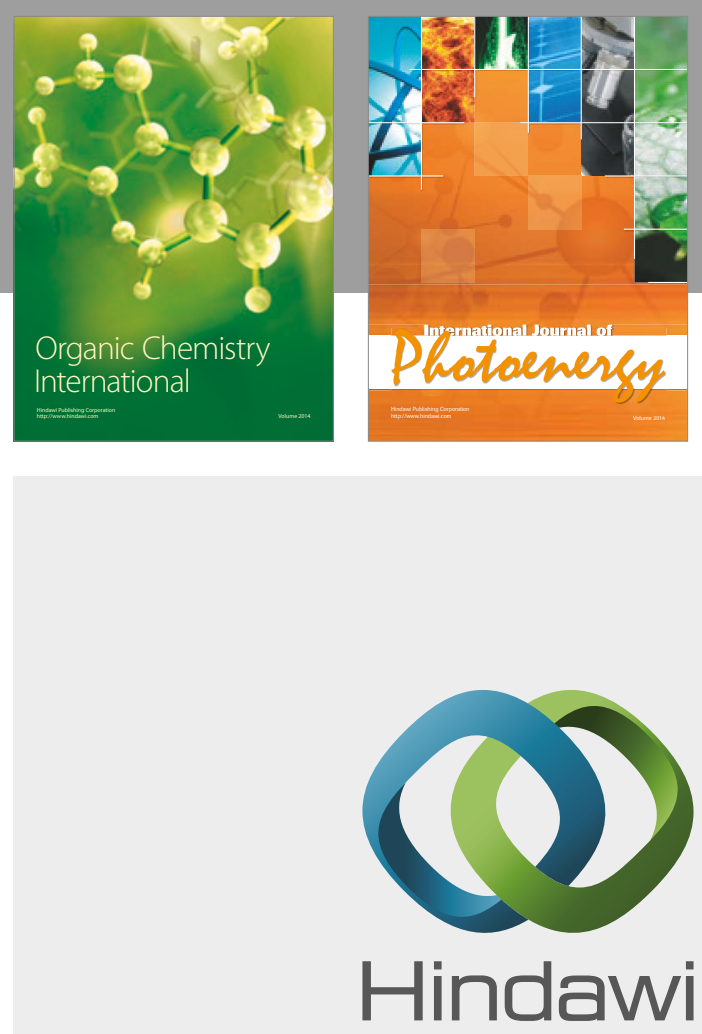

Submit your manuscripts at

https://www.hindawi.com

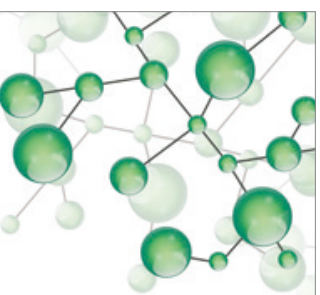

International Journal of

Inorganic Chemistry

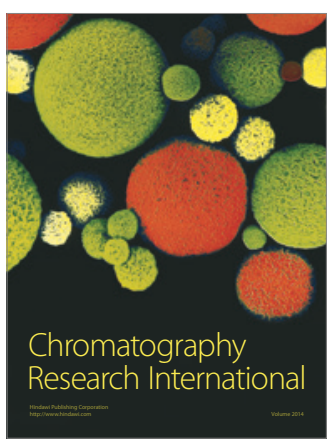

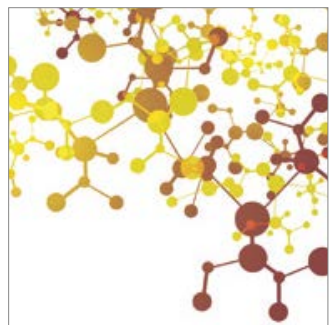

Applied Chemistry
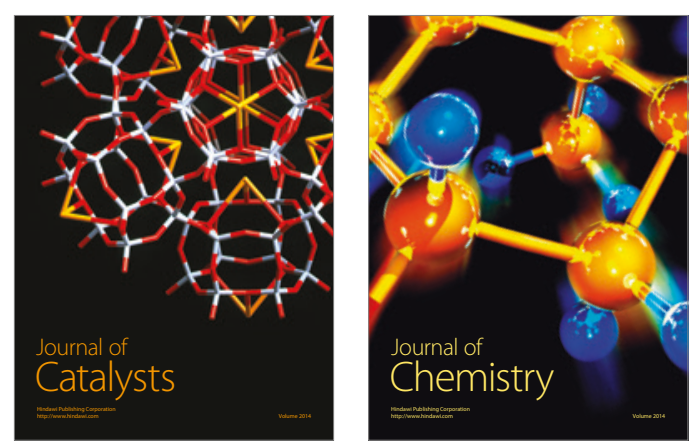
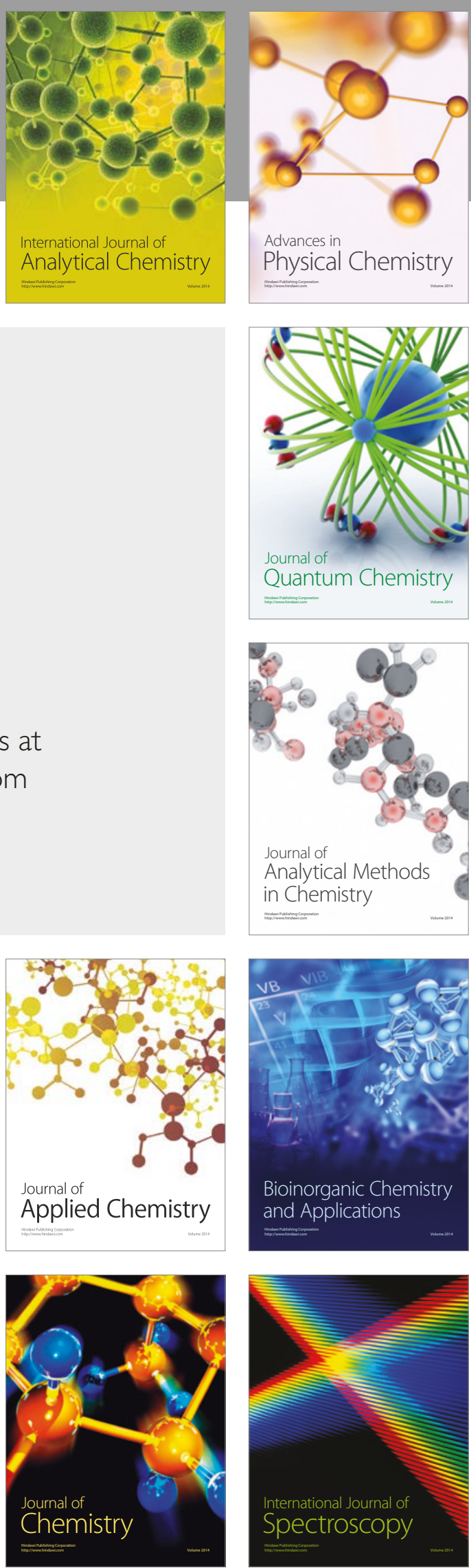